\author{
Stawomir Judek \\ Krzysztof Karwowski \\ Politechnika Gdańska, \\ Wydziat Elektrotechniki i Automatyki \\ Lech Lipiński \\ Mirostaw Miszewski \\ PESA Bydgoszcz S.A.
}

\title{
Modelowanie i symulacja napędów elektrycznych kolejowych pojazdów trakcyjnych z silnikami indukcyjnymi
}

\begin{abstract}
$W$ artykule zaprezentowano model trakcyjnego układu napędowego dla elektrycznego pojazdu kolejowego. Model utworzono w środowisku Matlab/Simulink. Odwzorowuje on działanie silników indukcyjnych z algorytmem sterowania silnika wedtug metody polowo-zorientowanej RFOC z regulatorami pradów typu PI z ograniczeniami sygnatów wyjściowych. Model sparametryzowano oraz przetestowano $w$ zakresie poprawności działania. Uzyskane wyniki symulacyjne zweryfikowano z przebiegami rzeczywistymi uzyskanymi podczas jazdy na odcinku testowym. Opracowany model umożliwia wygodnq analize parametrów pojazdu. Wyznaczono energochtonność pojazdu z uwzględnieniem wpływu parametrów sterowania.
\end{abstract}

\section{Wstęp}

Nowoczesne pojazdy sieciowe, a w szczególności elektryczne zespoły trakcyjne (EZT), charakteryzują się wzrostem pobieranej mocy z sieci trakcyjnej oraz wysoką złożonością napędu energoelektronicznego. Zawansowane metody sterowania napędem i całym pojazdem oraz wysokie wymagania jakości regulacji i niezawodności pracy wymuszają szczegółową analizę pracy EZT, zwłaszcza że pojazdy te charakteryzują się dużą dynamiką jazdy. Dodatkowo parametry elektryczne zasilania trakcyjnego oraz napędu wnoszą ograniczenia i są wzajemnie powiązane $[2,6]$.

Analiza układu napędowego nowoczesnego EZT wymaga opracowania modeli matematycznych odwzorowujacych poszczególne komponenty napędu oraz zdefiniowania ich wzajemnych powiązań. W literaturze, w zależności od problematyki analizy, spotyka się modele o zróżnicowanym stopniu dokładności $[1,2,6]$. $Z$ jednej strony są prezentowane złożone modele odwzorowujące różne metody sterowania silnikami trakcyjnymi, nawet wraz ze współpracą z przekształtnikami energoelektronicznymi czy mechanicznym układem transmisji momentu $[2,5]$. Komputerowe obliczenia symulacyjne w tych przypadkach sa czasochłonne, zwłaszcza dla symulacji pracy przekształtnika energoelektronicznego, charakteryzującego się dużą szybkością zmian napięcia. Prowadzi to do znacznego skracania kroku całkowania numerycznego i wydłużania czasu obliczeń numerycznych. Z drugiej strony zachodzi potrzeba wykonywania obliczeń związanych $\mathrm{z}$ analizą współpracy zasilania trakcji z poruszającymi się pojazdami. Dotychczasowe metody opierają się na tzw. „przejeździe teoretycznym", uwzględniającym parametry napędu jedynie w postaci ogólnej charakterystyki trakcyjnej pojazdu [6].

Wzrost szybkości obliczeń komputerowych umożliwia przeprowadzenie symulacji ruchu pojazdów na podstawie dokładniejszych modeli układu napędowego niż jego charakterystyka trakcyjna. Przykładowa analizę zaprezentowano dla modelu układu napędowego elektrycznego zespołu trakcyjnego ED-74 opierając się na wektorowym sterowaniu polowozorientowanym dla silników indukcyjnych [5]. Zaimplementowano metode sterowania wektorowego napędu dla ciagłego układu dynamicznego, tj. bez przekształtników energoelektronicznych. Konwersja zmian parametrów energii prądu stałego DC dostosowana jest do parametrów przebiegów zmiennoprądowych AC dla harmonicznej podstawowej, gdyż nie modeluje się sterowania impulsowego PWM falowników napędu.

\section{Układ napędowy zespołu trakcyjnego i jego para- metry}

Rozpatrywany EZT typu ED-74 wyposażony jest $\mathrm{w}$ napęd przekształtnikowy prądu przemiennego $\mathrm{z}$ silnikami indukcyjnymi. Uproszczony schemat blokowy układu głównego pojazdu przedstawiono na rys. 1. Pojazd napędzany jest przez cztery silniki o łącznej mocy znamionowej wynoszacej $2 \mathrm{MW}$. Podstawowe dane pojazdu oraz jego napędu przedstawiono w tabl. $1[3,4]$.

Każdy z silników trakcyjnych zasilany jest za pośrednictwem osobnego falownika tranzystorowego wykonanego $\mathrm{w}$ technologii IGBT. W falownikach wykorzystywana jest modulacja szerokości impulsów 
PWM [1]. W sterownikach napędów, opartych na procesorach sygnałowych, zaimplementowano wektorową regulację momentu wykorzystującą metodę RFOC $[1,5]$. Metoda ta pozwala na odsprzężone sterowanie momentu elektromagnetycznego oraz strumienia silnika poprzez regulację prądów stojana silnika $i_{d}, i_{q}$ wyrażonych w wirującym układzie współrzędnych, związanym $\mathrm{z}$ wektorem strumienia wirnika silnika [5]. Pracę czterech napędów koordynuje układ sterowania pojazdem.

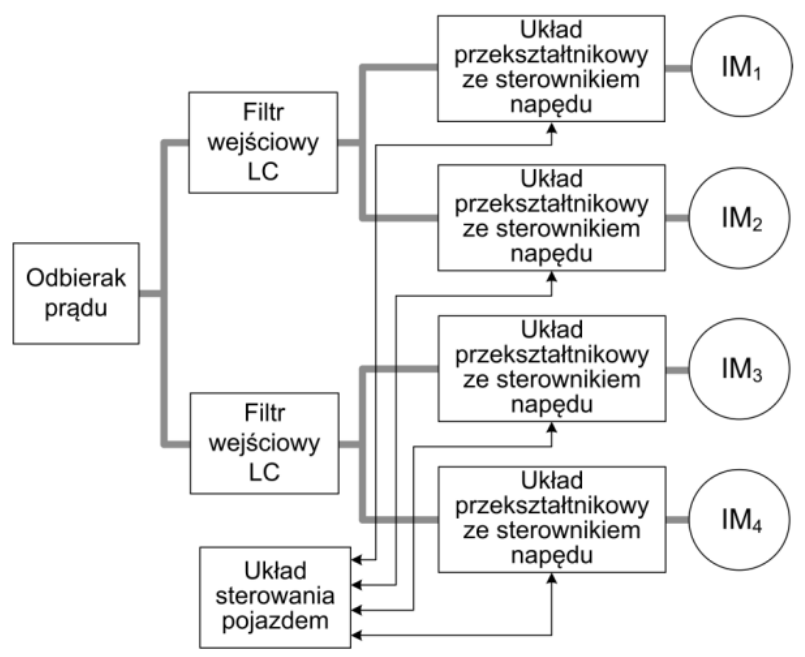

Rys. 1. Schemat blokowy układu napędowego EZT typu ED-74

\section{Podstawowe dane EZT ED-74}

Tabela 1

\begin{tabular}{|l|c|}
\hline Masa służbowa pojazdu & $156 \mathrm{t}$ \\
\hline Prędkość eksploatacyjna pojazdu & $160 \mathrm{~km} / \mathrm{h}$ \\
\hline $\begin{array}{l}\text { Przyspieszenie pojazdu do prędkości } 50 \\
\mathrm{~km} / \mathrm{h}\end{array}$ & $1 \mathrm{~m} / \mathrm{s}^{2}$ \\
\hline Moc znamionowa & $2 \mathrm{MW}$ \\
\hline Liczba silników trakcyjnych & 4 \\
\hline Maksymalny moment na wale silnika & $4400 \mathrm{Nm}$ \\
\hline $\begin{array}{l}\text { Maksymalna prędkość kątowa wirnika } \\
\text { silnika }\end{array}$ & $\begin{array}{c}5200 \mathrm{ob}- \\
\mathrm{r} / \mathrm{min}\end{array}$ \\
\hline Maksymalny prąd wyjściowy falownika & $250 \mathrm{~A}$ \\
\hline $\begin{array}{l}\text { Maksymalne napięcie wyjściowe falow- } \\
\text { nika }\end{array}$ & $2340 \mathrm{~V}$ \\
\hline
\end{tabular}

Charakterystykę trakcyjną EZT oraz wynikające stąd zadawane wartości składowych prądów $i_{d}$ oraz $i_{q}$, odpowiadających za generowany moment silnika, można podzielić na trzy obszary wynikające $\mathrm{z}$ zależności opisującej moment rozwijany przez silnik indukcyjny $[1,4]$. Pierwszy przedział, to praca ze stałym momentem. Przy zwiększaniu prędkości następuje przejście na pracę do stałej mocy. Moment jest wtedy odwrotnie proporcjonalny do rozwijanej prędkości kątowej. Ostatni fragment charakterystyki, dla największych prędkości jazdy, uzyskiwany jest przy pracy ze stałym poślizgiem silnika, co wiąże się z ograniczeniem mocy napędu.

\section{Model pojazdu i napędu elektrycznego}

Model, opracowany w środowisku Matlab/Simulink, ma strukturę modułową. Poszczególne moduły odwzorowują pracę: silników indukcyjnych, idealnego przekształtnika DC/AC, sterowników napędów, filtrów wejściowych pojazdu typu $\Gamma$ oraz podstacji zasilającej z siecią trakcyjną. W sterownikach napędów zaimplementowano algorytm sterowania według metody RFOC z regulatorami prądów typu PI. Model sparametryzowano oraz przetestowano $\mathrm{w}$ zakresie poprawności działania. Ogólną strukturę modelu przedstawiono na rys. 2.

Wartości prądów zadawane są w bloku kalkulacji prądów referencyjnych na podstawie zadawanych wartości momentu. Regulatory prądów wykonano jako proporcjonalno-całkujące (PI) z ograniczeniem całki oraz wartości wyjściowej. Regulacja prądów według metody RFOC odbywa się w układzie współrzędnych $d, q$ związanym ze strumieniem magnetycznym $\psi_{r}$ wirnika silnika.

Do wartości wyjściowych $\mathrm{z}$ regulatorów PI dodawane są napięcia obliczone przez blok odsprzęgający tory regulacji. Zadane napięcia są transformowane do stacjonarnego układu współrzędnych. Transformacja uwzględnia możliwości realizacji zadanego napięcia silnika z wykorzystaniem bieżącej wartości napięcia obwodu pośredniego.

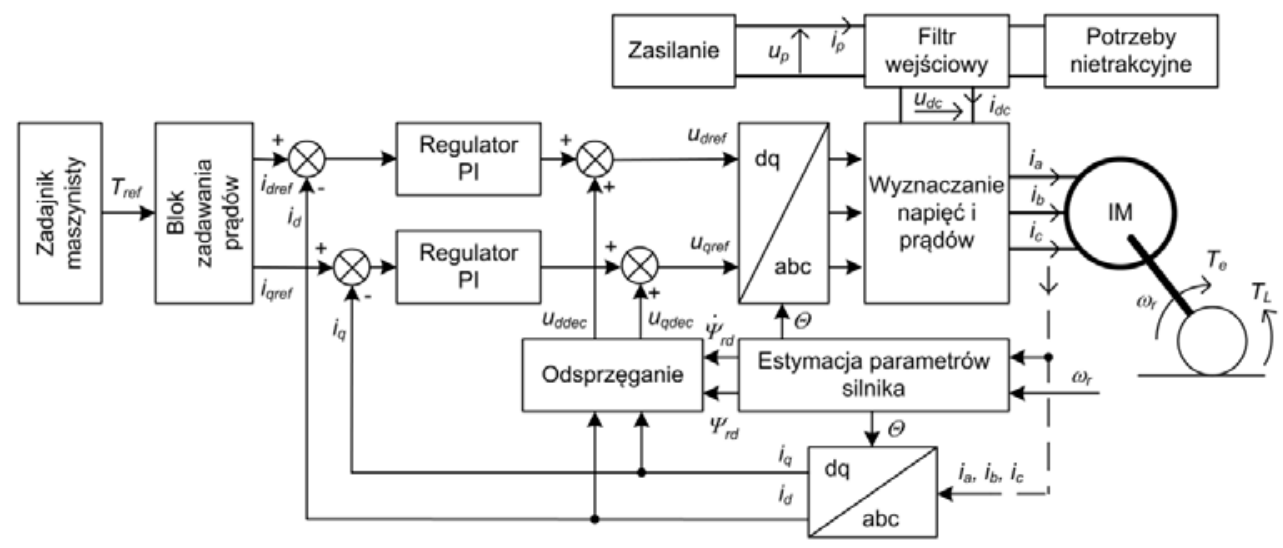

Rys. 2. Ogólna struktura modelu symulacyjnego układu napędowego 
W opisie analitycznym silnika zastosowano uproszczenia polegające na założeniu symetrii maszyny i sinusoidalnym rozkładzie uzwojeń oraz pominięciu: zjawiska histerezy, nasycenia magnetycznego, wyższych harmonicznych rozkładu przestrzennego pola w szczelinie powietrznej. Ponadto rezystancje uważa się za stałe, a odpowiednie indukcyjności za stałe lub zależne tylko od położenia. Opis pracy silnika, oparty na równaniach we współrzędnych naturalnych $a, b, c$, wymaga znajomości kąta położenia wirnika względem stojana $\theta$. Z tego względu dokonuje się przekształcenia (transformacji) układu równań do ortogonalnego układu współrzędnych $d, q$. W celu wprowadzenia zwięzłego opisu równań $\mathrm{w}$ nowym układzie współrzędnych wykorzystano zapis w postaci amplitud zespolonych i teorię tzw. wektorów przestrzennych [5]. Wszystkie parametry silnika związane $\mathrm{z}$ wirnikiem sprowadza się do obwodu stojana.

Zastosowany model jest opisywany standardowymi równaniami napięciowo-prądowymi [5] wyrażającymi wartość momentu elektromagnetycznego generowanego przez silnik:

$$
T_{e}=\frac{p}{2} \Psi_{\mathrm{r} d}\left(\frac{L_{\mathrm{m}}}{L_{\mathrm{r}}} i_{\mathrm{s} q}\right)
$$

gdzie: $\psi_{\mathrm{r} d}$ - składowa strumienia wirnika, $L_{\mathrm{m}}$ - indukcyjność główna silnika, $L_{\mathrm{r}}$ - indukcyjność wirnika silnika, $i_{\mathrm{s} q}$ - składowa prądu stojana, $p$ - liczba biegunów.

Wielkościami wejściowymi, zaimplementowanego w środowisku Simulink, modelu są napięcia fazowe silnika $u_{a}, u_{b}, u_{c}$ oraz parametry obwodowego modelu silnika. Wielkości wyjściowe modelu stanowią prądy fazowe pobierane przez silnik $i_{a}, i_{b}, i_{c}$, prędkość mechaniczna $\omega_{r}$ oraz składowe strumienia magnetycznego skojarzonego $\mathrm{z}$ wirnikiem odpowiednio $\psi_{\mathrm{rd}} \mathrm{i}$ $\psi_{\mathrm{r} q}$.

Na rys. $3-5$ przedstawiono przykładowe przebiegi względnych wartości prądów i napięć silnika podczas rozruchu i zadawania różnych wartości momentu. Zadawane wartości momentu $\mathrm{w}$ dłuższym przedziale czasu zobrazowano na rys. 7 . Ze względu na przyjętą skalę czasu na rys. 3a pokazano przebiegi prąóow fazowych silnika, na których widoczne są wartości maksymalne. Zmiana wartości zadawanego momentu $T_{\text {ref }}$ powoduje zmiany prądów referencyjnych (rys. 2). Układ sterowania zadaje wartość prądu $i_{d}$ odpowiedzialną za strumień silnika $\Psi_{\mathrm{r}}$. Dopiero po ustaleniu się wartości strumienia rozpoczyna się regulacja prądu $i_{q}$ odpowiedzialnego za moment elektromagnetyczny $T_{\mathrm{e}}$. Wraz ze zwiększaniem prędkości kątowej $\omega_{r}$ wartości zadane prądów odpowiednio zmieniają się zapewniając realizację założonej charakterystyki trakcyjnej $T_{\mathrm{e}}=f\left(\omega_{r}\right)$. W trakcji elektrycznej napięcie zasilania może się zmieniać w szerokich granicach. Wpływ ograniczenia napięcia zasilania $\mathrm{z}$ sieci trakcyjnej na pracę silnika pokazano na rys. $3 b$. Na rys. 3a widoczny jest wtedy szybszy wzrost wartości pradów silnika.

a)

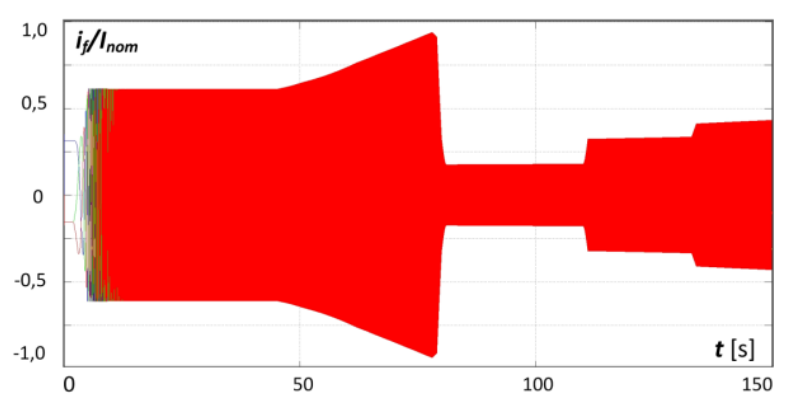

b)

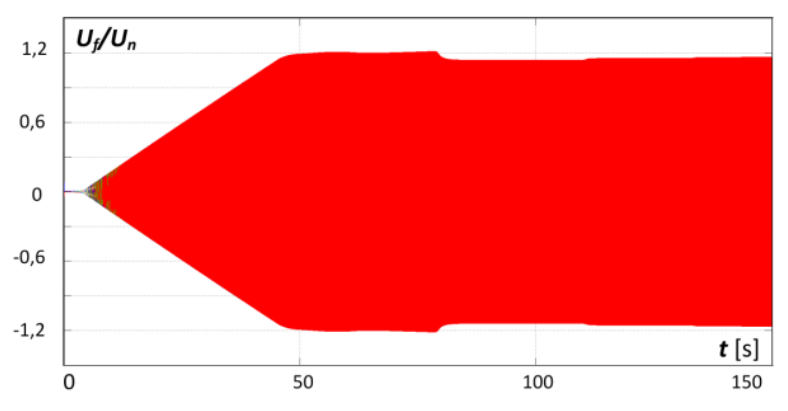

Rys. 3. Przebiegi prądów i napięć silnika dla wybranego trybu zadawania momentu napędowego z rys. 6: a) przebiegi prądów fazowych silnika; b) przebiegi napięć fazowych silnika

Przebieg jednego $\mathrm{z}$ prądów fazowych silnika $\mathrm{z}$ rys. 3 przedstawiono $\mathrm{w}$ rozszerzonej skali czasu na rys. 4. Przeliczanie wartości prą̧ów silnika do obwodu zasilania z filtrem wejściowym pozwala na wyznaczenie obciążenia zasilania trakcyjnego. Na rys. 5 pokazano wyznaczony prąd pojazdu dla fragmentu przejazdu z rys. 6 .

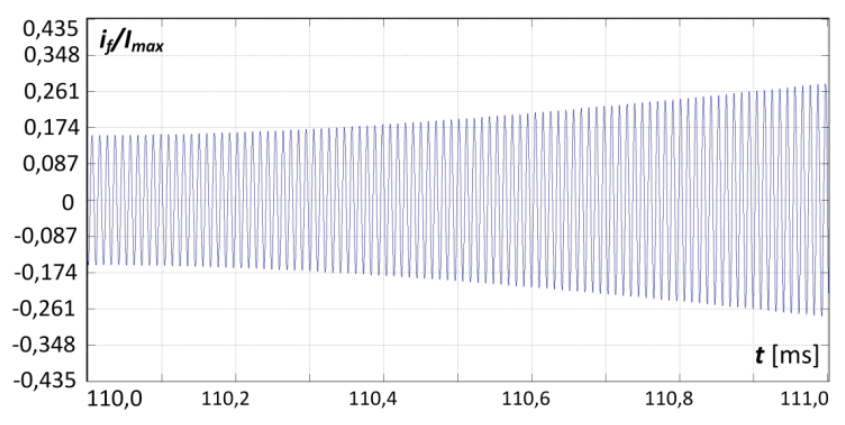

Rys. 4. Fragment przebiegu prądu jednej fazy silnika

W pojeździe zainstalowane są dwa filtry wejściowe przekształtników. Filtry tego typu są filtrami pasywnymi LC o strukturze $\Gamma$. Na potrzeby symulacji zamodelowano układ filtru $\mathrm{z}$ uwzględnieniem rezystancji dławika:

$$
\frac{\mathrm{d} u_{\mathrm{dc}}}{\mathrm{d} t}=\frac{1}{C_{\mathrm{f}}}\left(i_{\mathrm{p}}-i_{\mathrm{dc}}\right)
$$




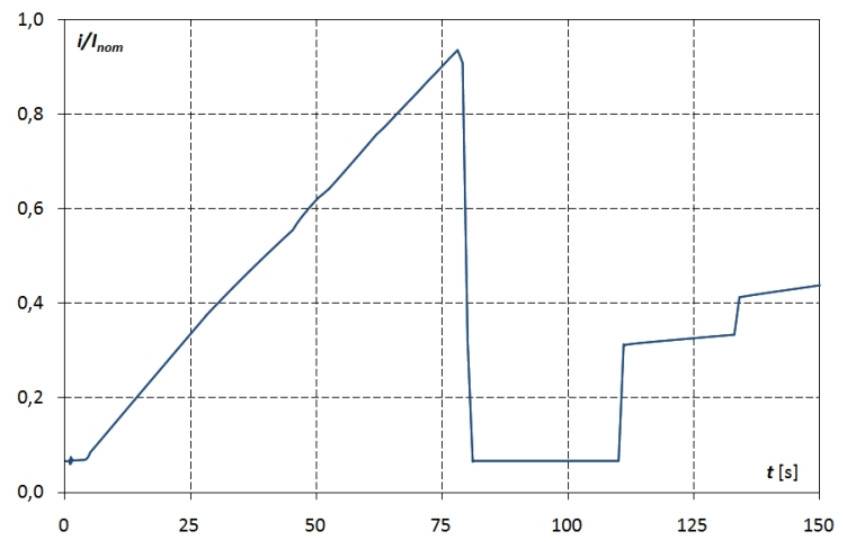

Rys. 5. Przebiegi prądu pojazdu dla wybranego zadawania momentu napędowego

$$
\frac{\mathrm{d} i_{\mathrm{p}}}{\mathrm{d} t}=\frac{1}{L_{\mathrm{f}}}\left(u_{\mathrm{p}}-u_{\mathrm{dc}}-R_{\mathrm{f}} i_{\mathrm{p}}\right)
$$

gdzie: $u_{\mathrm{dc}}$ - napięcie $\mathrm{w}$ obwodzie pośrednim falowni$\mathrm{ka}, i_{\mathrm{dc}}$ - prąd pobierany przez falownik, $u_{\mathrm{p}}$ - napięcie zasilające pojazd (przed filtrem), $i_{\mathrm{p}}$ - prąd pobierany $\mathrm{z}$ sieci, a $R_{\mathrm{f}}, L_{\mathrm{f}}, C_{\mathrm{f}}-$ odpowiednio rezystancja, indukcyjność i pojemność filtru.

Wybrano układ zasilania jednostronnego z podstacją trakcyjną zamodelowaną w uproszczony sposób w postaci źródła napięcia stałego i rezystancji wewnętrznej. Odcinek sieci trakcyjnej zamodelowano poprzez elementy skupione opisujące odpowiednio rezystancję i indukcyjność sieci. Model zasilania modyfikuje parametry użyte we wzorach (2) i (3).

\section{Badania symulacyjne ruchu pojazdu i układu na- pędowego}

Przykładowe wyniki badań symulacyjnych obrazujące wybrane możliwości modelowania układu napędowego zamieszczono na rys. $6-9$. Na rys. 6 przedstawiono przebiegi prędkości zespołu i siły trakcyjnej rozwijanej przez napęd podczas eksperymentalnego przejazdu. Rys. 6a zawiera wyniki uzyskane z pomiarów za pośrednictwem rejestratora cyfrowego $\mathrm{z}$ okresem próbkowania $1 \mathrm{~s}$, na rys. $6 \mathrm{~b}$ zobrazowano zaś wyniki symulacji komputerowej. Wyniki przedstawiono w skali względnej, odniesionej do maksymalnych parametrów pojazdu. Do celów symulacji przyjęto zadawane wartości siły analogicznie, jak w eksperymencie, tj. co sekundę zadawano nową wartość zgodną $\mathrm{z}$ wartością wytwarzaną przez zadajnik pojazdu. Nieznaczne różnice pomiędzy wynikami pomiarowymi a symulacyjnymi wynikają $\mathrm{z}$ przybliżonych danych zasilania i pojazdu (np. opory ruchu, napięcie zasilania), uproszczonego modelu napędu wraz z układem sterowania. Symulacje oparte na przedstawionym modelu sa szybko realizowane, np. na standardowym komputerze PC przebiegi te wyliczono w czasie ok. $100 \mathrm{~s}$. a)

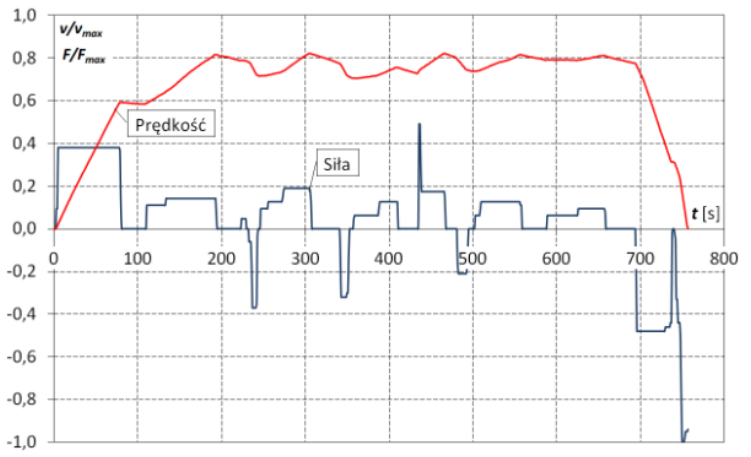

b)

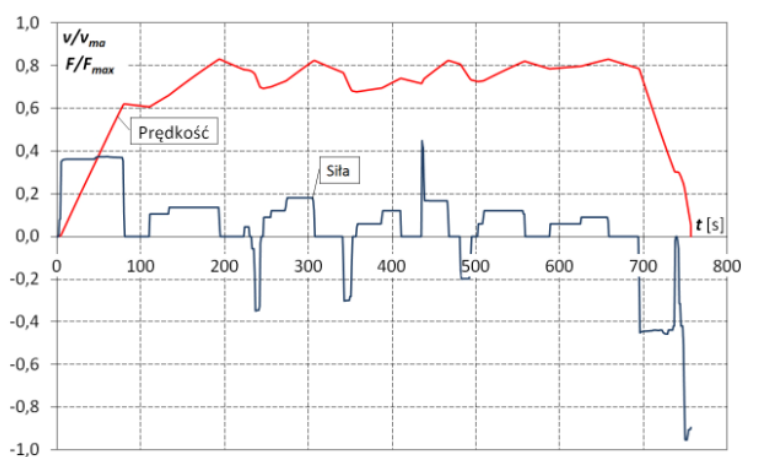

Rys. 6. Przebiegi prędkości i siły trakcyjnej dla przejazdu zespołem ED-74: a) wyniki pomiarowe; b) wyniki symulacji komputerowej

Odpowiednio do zadawanych wartości momentu napędowego zmieniają się prądy silników. Prąd pobierany przez zespół przedstawiono na rys. 7 - w przypadku hamowania bez odzysku i z odzyskiem energii. Wyniki pomiarów prądu, uzyskane podczas przejazdu, odniesiono do prądu nominalnego pojazdu.
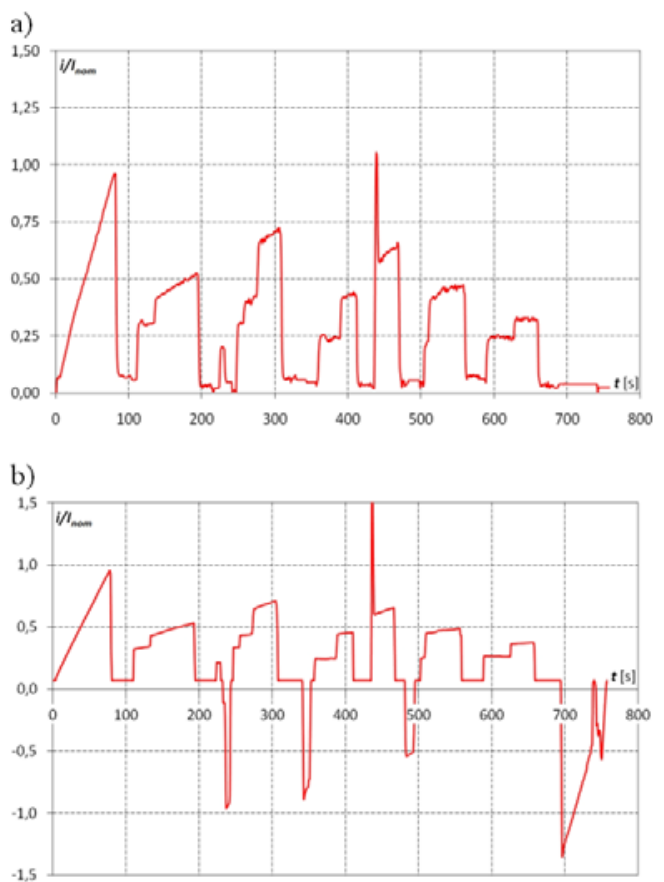

Rys. 7. Przebiegi prądów pojazdu zmierzone podczas przejazdu pojazdu przy zadawaniu siły według rys. 6a: a) w przypadku hamowania bez odzysku energii; b) z realizacją hamowania odzyskowego 
Analogicznie do zadawanych wartości dla przebiegów z rys. 7 przeprowadzono symulacje, których wyniki zaprezentowano na rys. $8 . \mathrm{Z}$ porównania obu rysunków wynika dobra zgodność symulacji z pomiarami.

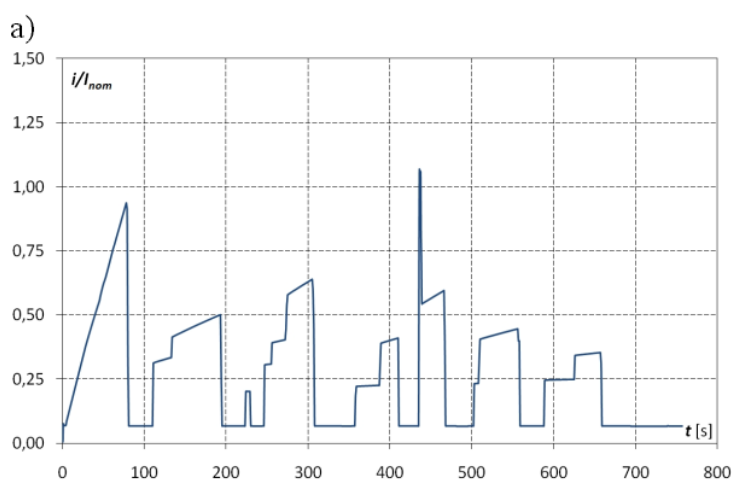

b)

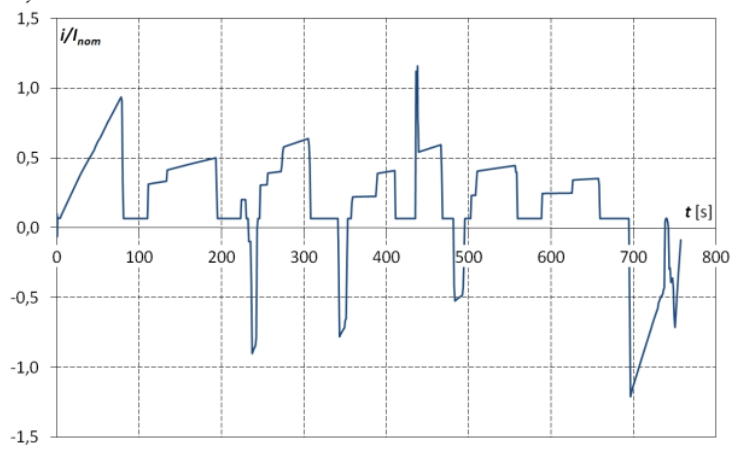

Rys. 8. Przebiegi prądów pojazdu uzyskane z symulacji podczas przejazdu pojazdu przy zadawaniu siły według rys. 6a: a) w przypadku hamowania bez odzysku energii; b) z realizacją hamowania odzyskowego
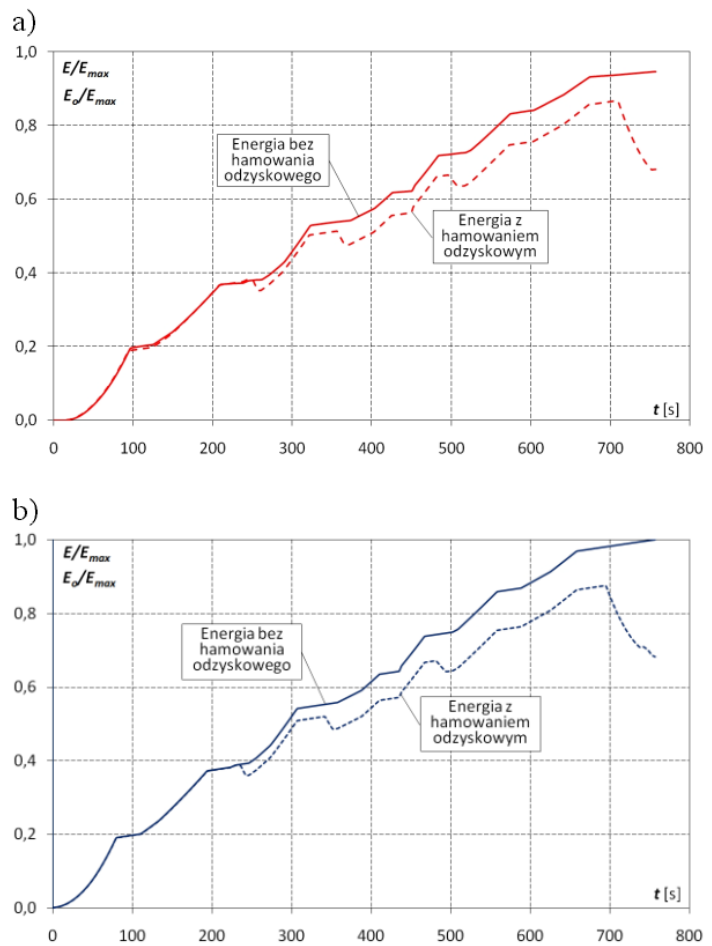

Rys. 9. Względne przebiegi energii zużytej podczas przejazdu bez uwzględnienia i z uwzględnieniem energii odzyskanej podczas hamowania dla przejazdu zespołu ED-74: a) wyniki pomiarowe; b) wyniki symulacji komputerowej
Dla zmierzonych lub obliczonych przebiegów prądów i napięć łatwo jest wyznaczyć energię zużywaną przez pojazd. Na rys. 9 przedstawiono względne przebiegi energii zużywanej podczas przejazdu bez uwzględnienia i z uwzględnieniem energii odzyskanej podczas hamowania. Przebiegi te odniesiono do wartości energii zużytej na przejazd, którą wyznaczono z symulacji. Wyznaczone przebiegi energii odnoszą się do przejazdu o danych według rys. 6 . W obliczeniach symulacyjnych uwzględniono stałą wartość mocy pobieranej na potrzeby nietrakcyjne, której wartość określono z przebiegu prądu przedstawionego na rys. 7.

\section{Podsumowanie}

Opracowany symulator umożliwia wygodną analizę wielkości niemierzalnych lub trudno mierzalnych, a także analizę wpływu parametrów programu sterowania oraz elementów układu napędowego na właściwości trakcyjne zespołu i układu zasilania elektrotrakcyjnego. W szczególności model symulacyjny stanowi praktyczne narzędzie wyboru struktury algorytmu sterującego i doboru parametrów regulatorów napędu. Uzyskane wyniki zweryfikowano z danymi rzeczywistymi pojazdu ED-74. Uzyskano dobrą zgodność wyników symulacyjnych z wynikami pomiarowymi zebranymi podczas jazdy testowej. Zaletą modelu jest także duża szybkość realizacji obliczeń symulacyjnych.

\section{Literatura}

[1] Jarzębowicz L., Judek S., Karwowski K., Miszewski M., Lipiński L.: Kompleksowa analiza symulacyjna uktadu napędowego zespołu trakcyjnego. XIV Ogólnopolska Konferencja Naukowa Trakcji Elektrycznej $i$ VI Szkoła Kompatybilności Elektromagnetycznej w Transporcie SEMTRAK 2010. Politechnika Krakowska. Zakopane 2010.

[2] Lewandowski M.: Analiza zjawisk elektromechanicznych $w$ szynowym pojeździe trakcyjnym z uwzględnieniem zmian wspótczynnika przyczepności kót napędowych. Oficyna Wydawnicza Politechniki Warszawskiej. Warszawa 2009.

[3] Lipiński L., Miszewski M.: Efektywność rekuperacji osiagana przez EZT-y serii ED74 na trasie Łódź Warszawa. Pojazdy Szynowe 1/2010.

[4] Lipiński L., Miszewski M.: Parametry trakcyjne elektrycznych zespołów trakcyjnych $w$ trakcji wielokrotnej przy ograniczeniu mocy pobieranej z sieci trakcyjnej. TTS 1-2/2010.

[5] Mohan N.: ADVANCED ELECTRIC DRIVES Analysis, Control and Modeling using Simulink ${ }^{\circledR}$. MNPERE Minneapolis 2001.

[6] Szelag A.: Zagadnienia analizy i projektowania systemu trakcji elektrycznej pradu statego z zastosowaniem technik modelowania i symulacji. Oficyna Wydawnicza Politechniki Warszawskiej. Warszawa 2002. 